\section{Influence of Aggression Management Program in Reducing Aggressive Behavior of Filipino Children in Conflict with the Law}

\section{Consuelo Oliveros-Peralta; Jemerson N. Dominguez}

De La Salle University - Dasmariñas, Philippines

email: coperalta@dlsud.edu.ph

email: jemerson.dominguez@gmail.com
Journal PSIKODIMENSIA

Volume 19, No. 2,

Juli - Desember 2020

ISSN cetak : 1411-6073

ISSN online : $2579-6321$

DOI:10.24167/psidim.v19i2.2545

\begin{abstract}
Aggression is a behavior that intent to hurt others. Despite collective researches about aggression, there is a dearth in fully established psychosocial programs for the Children in Conflict with the Law (CICL) and evaluating program directed to aggressive behavior in the Philippines. Eight CICL housed in an institution under the supervision of the DSWDDasmariñas were the primary source of data. The study seeks to describe the pre-and-post mean scores of aggressions and determine the significant difference in aggression reduction before and after exposure to AMP. Employing the quasi-experimental design, the researchers administered the intervention and conducted repeated-measures to measure the effectiveness of AMP thru combined approaches of CBT-EFT in reducing their aggression level. Findings revealed that their aggression in the areas of physically aggressive responses, and verbally aggressive reactions were diminished after participating in the AMP, with the inclusion of counseling sessions in addressing problematic concerns related to aggressive behavior.
\end{abstract}

Keywords: aggressive behavior, Aggression Management Program (AMP), Filipino, Children in Conflict with the Law (CICL)

\section{INTRODUCTION}

The children in conflict with the law (CICL), used to be known as juvenile delinquent refers to a person under the age of 18 years who is alleged as, accused of, or adjudged as, having committed an offense under Philippine laws. (Mosquito, 2009; www.dswd.com) Although the population of CICL across the country seems to have decreased (www.pnp.com), it remains a major concern among authorities, The continuing participation of children abetted by media hype to crimes, especially those below 15 years old, is an upsetting concern not only to the members of the juvenile justice system but also to the whole Philippine society.

Accordingly, public and private social institutions have been devising ways to provide necessary intervention in handling these children in conflict with the law. The Juvenile Justice and Welfare Act 2006 also known as Republic Act 9344, for example, ensures the protection and safety of juveniles who commit crimes. RA 9344 states that when a juvenile in custody is under the age of 15 , the juvenile is released to parents, guardian or closest relatives. The intension of the Republic Act is to avoid placing the juvenile in the jail system. However, in some cases where the family admits inability to handle the children, social institutions like the Department of Social Welfare and Development (DSWD) handle these children. Here, the CICLs face a diversion system that provides rehabilitation for the offense, including 
counseling, court-ordered activities or education to address their needs while they are away from their families. The goal of these rehabilitations is to prepare them for reintegration later on. Meanwhile, those who are 15 years and above but below 18 and who are already legally liable for the offenses committed, are dragged in institutions while waiting for the resolution of their cases. During their stay, these children are given intervention programs so that after the cases filed against them are resolved, they are deemed capable of handling life challenges outside the institutions.

However, there are instances where even with the prolonged stay in sheltered institutions for several months, these children continue to commit crimes. Schumacher and Kurz (2000) call these children recidivists. These recidivists put the efficacy of intervention programs in question. Questions persist as to the actual effect of these programs to decrease if not totally eradicate recidivists. More to the point, questions also linger if aggressive behavior between and among CICLs can be addressed by these programs. Studies on effective intervention programs for serious juvenile offenders (Cothern, Lipsey, \& Wilson, 2000; MacKenzie as cited in Adams \& Gullota, 2005), indicate that quite often these programs and trainings are aimed at developing interpersonal skills. Moreover, behavioral methods with reinforcements for clearly identified, overt behaviors have the most positive effects for the institutionalized serious offenders.

Although anger is seen by some researchers (Cornell et al. as cited in Goldstein et al., 2007) as neither essential nor adequate to produce aggressive behavior, they recognize its role in escalating aggressive behavior. Hence, anger management is included as one of the intervention programs appropriate for young offenders. Beck and Fernandez (1989) summarized the central features of anger management into three phases. The first phase includes Identification of situational triggers that precipitate the onset of the anger responses and rehearsal of self-statements intended to reframe the situation and facilitate healthy responses. Phase two includes acquisition of relaxation skills and coupling cognitive self-statements with relaxation after exposure to anger triggers with clients attempting to mentally and physically soothe themselves. Phase three includes rehearsal phase, exposure to trigger utilizing imagery of role play, and practicing cognitive and relaxation techniques until the mental and physical responses can be achieved automatically on cue.

Though there is at large a hanging suspicion as to the effectiveness of intervention to control, manage or eradicate aggression among young people in both macro (across various places in any given time) and micro (specific institutionalizes areas), still the efforts persist (Farrington, Loeber \& Kalb, 2007). In general, the idea of introducing anger management to crime offenders did not begin with juvenile offenders but with adults' offenders, specifically in relation to managing disruptive and often times criminal behaviors in prison cells (Towl, 1994).

The development of anger management in US prison cells gained momentum in the late 1980s where the initial aim was to address anger and aggression among prisoners, and was expected to reduce disruptive bahaviors (Hughes, 1993; Hunter, 1993). From the reports of Hughes (1993) and Hunter (1993) success of such programs was documented. Succeeding studies also pointed to successful intervention. An example of this study was conducted among 87 prisoners who were initially assessed for a possible anger management intervention (Ireland, 2004). The result showed that the experimental group used in the study showed significant improvements in all the measures of anger management 
intervention as compared to the controlled group.

Similarly, other previous studies showed successful results. An evaluated progress report, for example, among 50 adult prisoners using and pre and post measure analysis showed significant reduction of angry feelings that eventually resulted in successful anger management (Towl \& Dexter, 1994). Similar studies and interventions were also deployed among youth offenders. Escamilla (1998), for example, evaluated the impact of a anger management intervention among a sample of 16 juvenile offenders who completed a sixsession group intervention. The data showed that $25 \%$ of the sample population was not re-convicted for any offense, while $50 \%$ has re-offended but were not convicted of an aggressive offense. However, another $25 \%$ were convicted of an aggressive offense.

Between genders among youth, similar positive results of anger management programs were identified (Hermann \& McWhirter, 2003; Goldstein et al., 2007). In Hermann and McWhirter (2003), an anger management program called SCARE was deployed to a group of high school students who were considered as adolescents-at-risk for anger and aggression problems. The group of adolescents at risk with aggression was randomly assigned as experimental and control groups. The results showed the efficacy of the SCARE intervention program in addressing and preventing violence and aggression among youth at risk. Using female samples, on the other hand, Goldstein, Dovido, Kalbeitzer, Weil, and Strachan (2007) reported similar successful data using an anger management program for 12 girls in a juvenile institution. Although the researchers noted the limitations of the few samples, they however, noted that significant differences between the control and experimental groups leading to a positive result of anger management program. Further, the research also noted the promise of a larger-scale efficacy of the study.

Looking at various anger management programs deployed to children and adolescents, there are different models based on theoretical underpinnings as well as the area or type of aggression being identified. Such anger management programs include antecedent-behavior consequence model, skills training, rehearsal application, problem-solving, goal-setting, parent and teacher training, and other similar cognitive-behavioral therapies (Smith, Larson, Debaryshe, \& Salzman, 2000; Larson, Calaman, West, \& Frevert, 1998; Lochman, FitzGerald, \& Whiidby, 1999; Reid \& Webster-Stratton, 2001; Bank, Marlowe, Reid, Patterson, \& Weinrott, 1991).

Within the restorative frame of rehabilitation as specified by RA 9344, Cognitive-behavioral therapy can be a good source of intervention, especially in areas of cognitive, affect and behavioral rehabilitation of the child. In essence, the Cognitive-Behavioral Therapy (CBT) is an action-oriented form of psychosocial therapy that assumes that maladaptive, or faulty, thinking patterns cause maladaptive behavior and negative emotions among CICL. Other approaches which are found effective in managing anger are Emotion-Focused Therapy and Stress Inoculation Training. In a study attempting to decrease anger in male juvenile delinquents in Tehran (Sedrpoushan et al., 2012), anger management interventions called Emotion-Focused Therapy (EFT) and Stress-Inoculation Training (SIT) were deployed. The results were successful at some areas but were inconclusive in other areas of anger management. The results showed that the approaches were effective in decreasing state anger (emotional response to an immediate emotional stimulus) and verbal anger expression tendency. The results however showed that the anger 
management programs (EFT and SIT) did not have any effect on the rates of angry feeling and physical anger expression tendency. In addition, the results showed that the management approaches did not have any effect on the rates of anger trait (stable individual characteristics) and the two subscales: angry temperament and angry reaction. The use of EmotionFocused Therapy (EFT) has been visibly deployed in handling anger however, there are quite various settings with equally varying respondents that EFT was used.

In the Philippines, few studies have been deployed primarily to describe the situation of children in conflict with the law, identifying risk factors, and risktaking behaviors among Filipino adolescents and causes of delinquency (Templa et al., 2004; Alampay, Liwag, \& De La Cruz, 2009; Alampay, 2010). These researches provide significant findings about the profile of CICL including factors that contribute to their aggressive behaviors. Limited studies however, have been conducted to assess the effectiveness of Cognitive Behavioral Modification Program for aggressive children in conflict with the law. Corado (2004), for example, found that the aggression level of adolescents was reduced after teaching them skills in recognizing and managing anger, problem solving, as well as training them to use appropriate judgment in dealing with different social situations. Findings from this study confirm that aggressive behaviors may be managed. However, the challenge remains as to perform researches on the evaluation of theories and intervention implemented to children in conflict with the law considering the crucial impact of these studies in understanding the prevention to commit crimes among CICL.

In response to the aforesaid challenge, this research was performed. Specifically, the researchers intended to determine if the level of aggression of the CICL will be reduced by their participation in the Aggression Management Program which the researchers implemented.

\section{METHODS}

The research design of the study is quasi-experimental design due to limited group for comparison and no random assignment made. Working with AMP (as the independent variable) using modular approach, the researchers intentionally manipulate a single treatment group known as reversal design (ABA method). While, aggression serves as the outcome measure the researchers used to assess the change in behavior (Myers \& Hansen, 2014).

Participants, there were 31 CICL who were housed at Bahay Kalinga at the time the study was conducted. However, only 12 CICL who met the criteria set by the researchers participated in the study using purposive sampling. According to McBurney (2001), this sampling technique is appropriate with participants who are selected non-randomly based on the characteristics that they possess. The criteria were: (1) participants have case histories filed at the justice office of the City of Dasmariñas or are still waiting for the determination of their discernment; (2) residents of BK for at least two weeks; (3) children in the age bracket 15-17; (4) got high average to very high scores in the total AQ and in any of the five subscales of Aggression Questionnaire (AQ). While the program was ongoing, four of the participants were released to their family. Hence, only eight (8) CICL residents of Bahay Kalinga became the final participants of the study. Table 1 presents the profile of the participants about age, educational attainment, ordinal position, number of siblings and parents' marital status. 
Table 1. Profile of the Participants $(n=8)$

\begin{tabular}{|c|c|c|c|c|c|}
\hline Cases & Age & $\begin{array}{l}\text { Educational } \\
\text { Attainment }\end{array}$ & Ordinal Position & Number of Siblings & Parents' Marital Status \\
\hline Andy & 15 & Grade 6 & Youngest & $\begin{array}{l}5 \\
3 \text { from first marriage }\end{array}$ & Separated \\
\hline Bert & 17 & Grade 2 & Youngest & 6 stepsiblings & Separated \\
\hline Brad & 17 & $2^{21}$ Year HS & Second & 3 from first mamriage & Living together \\
\hline Conrad & 16 & Grade 1 & Second & $\begin{array}{l}2 \text { from first marriage } \\
3 \text { stepsiblings }\end{array}$ & $\begin{array}{l}\text { Separated } \\
\text { Mother deceased }\end{array}$ \\
\hline Denis & 16 & Grade 4 & Youngest & 5 & Father remarried \\
\hline Levy & 16 & Grade 0 & Second & 5 & $\begin{array}{l}\text { Father deceased } \\
\text { Mother remarried }\end{array}$ \\
\hline geclx & 16 & $1^{\text {sK }}$ Year HS & Second & $\begin{array}{l}1 \text { from first marriage } \\
1 \text { stepsibling }\end{array}$ & separated \\
\hline Toper & 17 & Grade 5 & Youngest & 1 & Separated \\
\hline
\end{tabular}

\section{Measures}

The following instruments were utilized: Aggression Questionnaire (AQ) as the standard measure and interview guide to validate the rate of aggression as the condition of timing progress.

Aggression Questionnaire (AQ). This was used to assess the aggression level of the participants before and after the implementation of the intervention. The AQ is a test made by Arnold H. Buss and W. L. Warren, an updated version of the Buss-Durkee Hostility Inventory (Buss \& Durkee, 1957), which is a longtime standard for assessing anger and aggression. The test is a brief measure consisting of 34 items scored on five scales- physical aggression, verbal aggression, anger, hostility, and indirect aggression. The AQ manual indicated that AQ items describe a characteristic related to aggression, and the individual taking the test rates the description on a scale from $1=$ "Not at all like me" to $5=$ "Completely like me." The items can be read and understood easily by anyone with at least a $3^{\text {rd }}$-grade reading ability. The test is considered helpful in clinical settings mainly for treatment planning since it provides scores in five subscales: Physical Aggression (includes eight items that focus on the use of physical force when expressing anger or aggression), Verbal Aggression (it has five items that pertain to quarrelsome and hostile speech), Anger (includes seven items that describe aspects of anger related to arousal and sense of control), Hostility (it has eight items that represent attitudes of bitterness, social alienation, and paranoia), and indirect aggression (with six items that measure the tendency to express anger in actions that avoid direct confrontation). It can be utilized to examine improvement of clients during intervention. The AQ Total score is based on the responses to all $34 \mathrm{AQ}$ items. "It is considered as a good summary measure of the general level of anger and aggression the individual has reported and is highly related to all of the five subscales but is most closely associated with the Physical Aggression and Anger subscale. The AQ Total score is based on statements pertaining to both the frequency.

Interview Guide. There were two sets of questionnaires written in Filipino language and with English translation. The first was used to gather in-depth information about the participants. It contained two open-ended questions. The first question aimed at extracting information about the life of the CICL before they were brought to Bahay Kalinga. By telling their stories, children revealed the circumstances that led them to commit their offenses. The second 
question was used to gather information about their problems and condition in Bahay Kalinga. On the other hand, the second questionnaire was utilized in the interview with the peers and the houseparents. The first part contained three open-ended questions which primarily derived information about the participants' behavior before the implementation of the intervention, based on the observation of the peers and the house-parents. The second part of the questionnaire had three open-ended questions which tried to collect information about the changes in the participants' behavior after their participation in the three modules (psychoeducational group activities) and individual counseling sessions.

\section{Procedures}

The research ran for three months from the administration of the test to the implementation of AMP.

1st Phase: Preparatory Stage. The researchers sought permission to conduct the study from the head of the Dasmariñas City Social Welfare and Development Office (Ms. Rose Abuan) in Dasmariñas-Cavite. We coordinated to schedule the pre-test measure using AQ. Initially, it was administered to 31 resident CICL in BK. During the administration, the researchers read each item in English, translated in Filipino and explained per word to ensure that the children understood the meaning of each item clearly. This was done throughout the test administration. The researchers attended to each participant to ensure that each item was answered, and all unnecessary marks were completely erased and that only the final answer to the 34-item test. The researchers scored and interpreted the pre-test. Only those who got high average to very high scores in the total AQ and in any of the five subscales of the test were included as participants of the study to eliminate the threat for regression. Initially, a total of 12 CICL qualified as participants. As call for ethical considerations, the researchers provide consent and ascent despite of the limited contacts with their parents. They affixed their signatures as a sign of agreement to participate in the program.

2nd Phase: Implementation of AMP. An orientation regarding the AMP was conducted. The participants were given information about the goals of the program, the schedule (i.e., dates and time) of the sessions and an overview of what is going to happen for the next eight weeks. To secure their commitment towards the study, they were requested to set their expectations from, self, peers, and from the facilitators before the first activity of AMP begins. The AMP composed of three modules was implemented through 11 sessions of skillbuilding group activities. The sessions were scheduled twice a week. Module-1 (anger management training) was implemented for five days and lasted for three weeks. While Module-2 (social skills building) emphasized on teaching the participants the skills in social problem-solving and conflict resolution strategies. It was implemented for three days and ran for one and half weeks. Module-3 (psychoeducational group activities) was on perspective-taking training. It provided the participants with the knowledge about hostility and empathy and helped them to become sensitive to other's feelings and thoughts and to develop non-biased judgment of their environment. All modules follow the essential activities like lecture, group discussion, feedback giving, modeling and dialogue rehearsal were utilized to accomplish the objectives included in each module. Likewise, the AMP included the individual counseling, which utilized the three phases of CBTEFT. It was conducted to facilitate deeper processing of the participants' problematic feelings and thoughts, which are shared during the group sessions. Verbal and nonverbal attending behavior of the researchers were the main techniques used to facilitate openness and disclosures of the participants during the 
sessions. One hour was the maximum time spent for each counseling session.

3rd Phase: Post Measures to Test the Influence of AMP. The AQ was administered to measure their post-test aggression level. Likewise, the researchers simultaneously did the recording, notetaking, and observation of the participants' experiences and reactions to the various activities of the AMP. Using a recorder, the counseling sessions with the eight participants were noted. The recorded sessions were transcribed verbatim for analysis and validation. Likewise, to record the participants' disclosures about their experiences in the group sessions, as well as their nonverbal reactions to the different activities, note taking and observation were performed by the researcher. All the data that were collected from the transcripts, notes, and observations about the participants' reactions and experiences during the eight weeks implementation of the AMP, were integrated and used in the analysis. The interview guide serves as validation of the statements elicited from their peers and the house-parents. It consists of two parts, with each part containing three open-ended questions. The goal of the first interview was to identify the aggressive behavior manifested by the participants, prior to their participation in the program which took place for two days While the objective of the other items was to describe the behavioral changes they exhibited after their participation in the three modules using the AMP intervention. Take note that the AQ was administered to the participants one week after the culmination of the AMP and re-administered after one month to validate if their aggression level relapsed.

Data Analysis, the study adheres to measure the aggression of eight CICL housed in Bahay Kalinga using AQ test by Buss and Warren (2008). The scores on the timing conditions such as pre-test (level 1), post-test (level 2), and delayed post-test (level 3) were determined using the repeated-measures of ANOVA. (Gravetter \& Forzano, Understanding Research Methods for Behavioral Sciences (2nd ed.), 2012).

\section{RESULTS}

Eight (8) case files were grouped together to get a full picture of the gathered data. The background of the participants was established as well as the history of offenses, to gain information about how the participants have developed their aggressive behavior leading to their offense. ABA or reversal method in single-subject design was delivered to gather data before and after the implementation of the program.

Level of Aggression Before and After Exposure to AMP

AQ test by Buss and Warren (2008) was utilized to obtain the reactions of each participant. This took part on showing the difference of the pre-test and post-test within the same group design.

Table 2. Descriptive Statistics of the Aggression Level

\begin{tabular}{|l|r|r|r|c|r|}
\hline & N & Minimum & Maximum & Mean & Std. Deviation \\
\hline Pretest & 8 & 57.00 & 66.00 & 61.3750 & 3.24863 \\
Posttest & 8 & 30.00 & 55.00 & 41.2500 & 7.59229 \\
Delayed & 8 & 31.00 & 48.00 & 36.8750 & 6.31184 \\
Valid N (listwise) & 8 & & & & \\
\hline
\end{tabular}

Table 2 shows the mean scores and standard deviation as standard measures of the cases' $(n=8)$ scores. The aggression level accumulated a pre-test mean score of $61.375(\mathrm{SD}=3.25)$ which indicated high aggression level. Case 2 was even 
highlighted with his distinctly high aggression as observed by his houseparent and peer. They said,

"he frequently engaged in fights, getting even when hurt, always saying vulgar words, cursing, telling jokes to make fun of others, keeping personal grudge."

While the garnered post-test mean score of $41.250(\mathrm{SD}=7.59)$ specified low average. This lead to a significant mean difference $(\mathrm{MD}=20.125)$. The change was evident in Case 5. His peers said,

"Mapagbiro pero di
nakakasakit, mabait at
mapagbigay na siya, at hindi na
siya nananakit". (He loves to
joke but it was not offensive, he
is even kind and generous, and no
longer causes harm.)

The house-parents mentioned, "Marunong makibagay, di biyolente at di nakakapanakit sa salita o sa pisikal man." (He knows how to conform, is no longer violent, and does not cause harm physically nor verbally.)

\section{Influence of AMP to Aggression Reduction}

After every session, as they are significant in determining the impact that the program has created upon the latter, the changes in the behavior of the participants were assessed collectively using the AQ scores to measure the effectiveness AMP in reducing their aggression using modular approach.

Repeated-measures of ANOVA was applied to determine the significant difference or change in aggression levels among participants after the intervention, since the data given (i.e. aggression) was repeatedly measured with the same participants. The intent of showing is to determine if everything is constant as far as individual difference is concerned, and the only source of variance is the aggression level.

Table 3. Repeated Measures of ANOVA (Within-Subjects)

\begin{tabular}{|ll|r|r|r|r|r|}
\hline Source & & $\begin{array}{c}\text { Type III Sum of } \\
\text { Squares }\end{array}$ & \multicolumn{1}{c|}{ df } & Mean Square & \multicolumn{1}{c|}{ F } & Sig. \\
\hline \multirow{5}{*}{ factorL } & Sphericity Assumed & 2731.750 & 2 & 1365.875 & 97.438 & .000 \\
& Greenhouse-Geisser & 2731.750 & 1.459 & 1872.922 & 97.438 & .000 \\
& Huynh-Feldt & 2731.750 & 1.745 & 1565.705 & 97.438 & .000 \\
& Lower-bound & 2731.750 & 1.000 & 2731.750 & 97.438 & .000 \\
& Sphericity Assumed & 196.250 & 14 & 14.018 & & \\
& Greenhouse-Geisser & 196.250 & 10.210 & 19.222 & & \\
& Huynh-Feldt & 196.250 & 12.213 & 16.069 & & \\
& Lower-bound & 196.250 & 7.000 & 28.036 & & \\
\hline
\end{tabular}

Table 3 underscores the obtained value $F_{o b t}(2,14)=97.438, p<.0001$. The $\mathrm{p}_{\text {value }}$ marks the distinction of significant difference was found among different assessment timing among the source of data such as: pre-test, post-test, and the delayed post-test scores on the aggressiveness of the participants. This can be validated using the assumed Sphericity test. Conversely, table 4 depicts the within subject contrast confirming that aggression levels after the intervention was significantly lower compared to aggression levels before the intervention, $F_{\text {obt }}(1,7)=76.40, p<.001$. Although, not statistically significant, aggression levels dropped one month after (delayed post-test) the given intervention, with the level of significance nearing the critical level, $F_{o b t}$ $(1,7)=5.31, p=.06$. 
Table 4. Test of Within-Subjects Contrast (Comparison)

\begin{tabular}{|c|c|c|c|c|c|c|}
\hline Source & factord & $\begin{array}{c}\text { Type III Sum of } \\
\text { Squares }\end{array}$ & df & Mean Square & $\mathrm{F}$ & Sig, \\
\hline \multirow{3}{*}{ factord } & Level 1 vs. Level 2 & 3240.125 & 1 & 3240.125 & 76.399 & .000 \\
\hline & Level 2 vs. Level 3 & 153.125 & 1 & 153.125 & 5.310 & .055 \\
\hline & Level 1 vs. Level 2 & 296.875 & 7 & 42,411 & & \\
\hline Error(facterid) & Level 2 vs, Level 3 & 201.875 & 7 & 28.839 & & \\
\hline
\end{tabular}

Legend: Pretest (level 1) at Post-test (level 2), Delayed post-test (level 3)

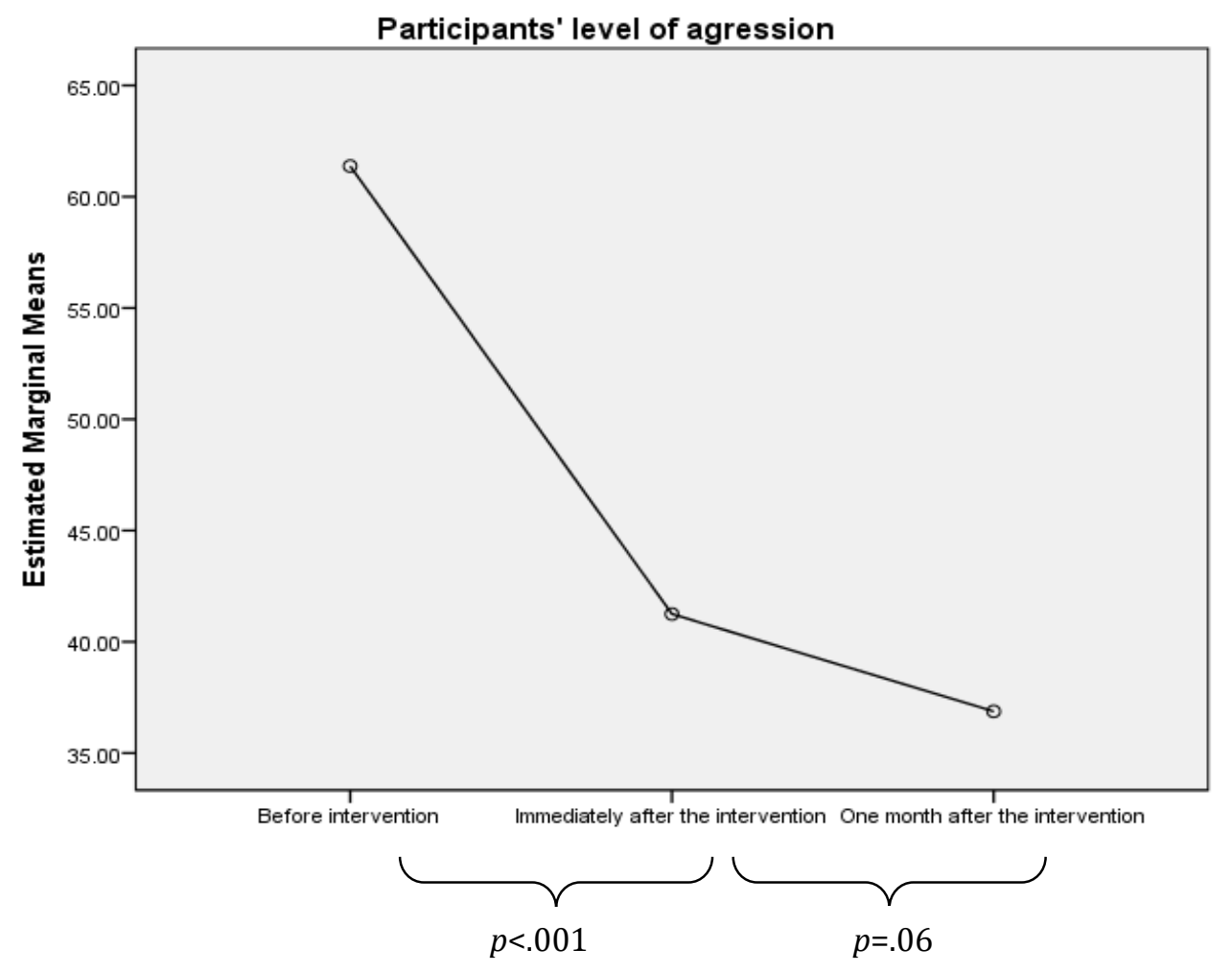

Figure 1. Participants Overall Level of Aggression

Figure 1 illustrates the extreme level on the shift of aggression reduction or diminished aggression level after being exposed to AMP that implies a significant difference. Alternatively, the dependent variable tends to post a trend that exhibits a gradual decrease that is not significant. This means that the state of aggression level among the participants diminished gradually after being exposed to the AMP.

\section{DISCUSSION}

Results indicate that the participants' level of aggression dropped from high to average and low which are indicative of relative absence of violent behavior and a strong capacity for selfcontrol which was achieved by the participants with the aid of the intervention. Specifically, it signifies that participants acquired the ability to manage physically aggressive impulses. 
The improvement in the participants' ability for self-control was confirmed in an interview with the house-parents and the peers, who noted several behavioral changes of the participants which include lack of involvement in trouble, and increased self-control manifested when exposed to teasing and/or bullying.

Furthermore, participants manifested the reticence to engage in verbal disagreements" (p. 14) and developed understanding to the thoughts and feelings of others, thus becoming more contented of their environment and more secure in establishing a relationship with other residents built with trust and support for each other. After conducting the perspective taking training, no report of participants getting involved in fighting incidents due to misinterpretation of the other residents' action was noted. This verifies that participants already developed sensitivity, which is essential in establishing a healthy relationship.

Notably, participants who experienced anger also showed some capacity to keep their reactions under control. They said that they tried to contain themselves from showing their anger because they did not want to be put in the isolation room and have more bad records. Results also signify that the participants have learned to express their anger in a more appropriate manner. This was indicated by reports of the houseparents and peers regarding participants' less frequent to absence of instances when they were observed as irritable and easily getting angry, which may be attributed with the anger management skills that they learned from the program.

Participants displayed capacity to deal with conflicts in a straight forward manner than indirect means. which was proven by the house-parents and other residents of the center. The participants have recognized that communication and listening to people who are involved are appropriate ways to handle conflicts.
The National Youth Violence Prevention Resource Center and Glick (1996) indicate that aggression is a serious and mounting concern among teens and that precarious behavior occurs during the late teen years and in early adulthood. Owen and Fox (2011) added that one of society's most serious concerns is youth offending and that it is necessary that this issue must be understood. The latter emphasized the necessity for intervention programs to address aggression of the participants as they are in their adolescent stage, the period which as mentioned is the time when they could be engaged in more risky behaviors.

Nonetheless, findings about the level of aggression indicate that after the implementation of the AMP, a downward trend in the participants' $T$ scores in the total AQ and in the five subscales of AQ have occurred. The results suggest that the aggression level was reduced from very high and high to average, low and very low levels. The reduction in the level of aggression of the participants may be attributed to the effectiveness of the combined approaches of CBT and EFT that were utilized in teaching the participants the appropriate emotional expression, self-control, emotional change, sensitivity, and to use adaptive behaviors in dealing with problematic and conflicting social situations. The findings about the changes in the aggression level could prove to the effectivity of AMP in improving the participants' behavior specifically in reducing aggression which is significant in preventing repeated offending was supported in the numerous studies using the cognitive behavioral approach. For example, Escamilla (1998) evaluated the impact of an anger management intervention among a sample of 16 juvenile offenders who completed a sixsession group intervention. The data showed that $25 \%$ of the sample population was not re-convicted for any offense, while a large 50\% re-offended 
but were not convicted of an aggressive offense. However, another $25 \%$ were convicted of an aggressive offense.

Still a more recent study confirmed the findings that improvements in the participants' aggressive behaviors were achieved after intervention. Rohde, Jorgense, Seeley, and Mace (as cited in Guerra et al., 2008) found that incarcerated youth after having subjected to cognitive intervention have achieved "significant improvements relative to controls, for a number of skills as well as for externalizing problems, which are most closely linked to antisocial behavior" (pp.85-86). This result was observed in the present study. The participants who had been externalizing their loneliness, boredom, anger, and worry by teasing or bullying that quite often led to fighting, have learned to use more effective ways of releasing their unpleasant feelings through breathing and relaxation, positive imagination, talking to other residents who they already learned to trust, writing in their diary, and doing chores at BK. In responding to the residents' teasing or bullying, and in dealing with miscommunication with the peers and the house-parents, the participants have learned to use effective social problemsolving such as communication and listening, diffusion, and avoidance.

The positive outcome of CBT in the present study is also supported by a local study involving institutionalized adolescents with aggression. Corado (2004) found that after teaching the adolescents the skills in recognizing and managing anger, problem solving, as well as training them to use appropriate judgment in dealing with different social situations, their aggression level has reduced. In the study, the evidence that the aggression level of the participants was reduced are indicated by the houseparents' and peers' report of less frequent to relative absence of physical and verbal aggressive behavior manifestations such as involvement in fights, getting even when hurt, saying bad words, arguing, and contradicting when dealing with the other residents, which may be attributed to greater emotional control that the participants have achieved after their participation in the AMP.

On the other hand, very few researches were found to support the positive outcome of combined CBT and EFT to adolescents with aggression. The study of Sedrpoushan et al. (2012) noted that the combined approaches of Emotion-Focused Therapy and Stress Inoculation Training improved the adaptive and coping skills of some juvenile delinquents in Tehran Correction Reformatory House. As a result, the children acquired increased capacity for controlling anger and reduced expression of anger.

Limbadan (2012) found that after using EFT in a 12-session group activity to select adolescents with high scores in anger, their posttest scores concerning the principles of emotional awareness and emotional regulation have both increased from average to high average, indicating a higher and increased level in emotional awareness, regulation and transformation. The higher overall posttest mean suggests effectiveness of the therapy. In this study, the effectiveness of the program can be measured through the disclosures of the participants indicating pleasant feelings, which were further established by their yearning to modify their behavior through increased practice of the skills that they learned concerning control of emotional reactions as they experience negative affect.

Although the study contributed additional knowledge in the field of research particularly on the issue of children in conflict with the law, it has still more areas for improvement. The researcher therefore recommends to those who would want to dwell on the issue of CICL particularly related on this study, to conduct an experimental study where 
more participants would be enjoined and where groupings would be based on the kind of intervention being received such as CBT alone, EFT alone, combined CBT-EFT, and no intervention, for the purpose of establishing the effectiveness of intervention embedded in the AMP.

\section{CONCLUSION}

The implementation of the psychoeducational group activities and individual counseling sessions resulted in the remarkable changes in the children's behavior as exhibited by the absence of aggressive behaviors which were made more obvious by the development of positive traits. CBT components are useful in teaching the CICL adaptive behavior, whereas EFT is a helpful therapy for processing the CICL's unresolved anger as well as in altering other unpleasant emotions.

\section{REFERENCES}

Adams, G. R., \& Gullota, T. P. (2005). Handbook of adolescent behavioural problems. Evidencebased approaches to prevention and treatment. NY, USA: Springer.

Alampay, L. P. (2006). Risk factors and causal processes in juvenile delinquency: Research and implications for prevention. Philippine Journal of Psychology, 39 (1), 195-228.

Alampay, L.P., De La Cruz, A. S., \& Liwag, C. D. (2009). Risk-taking among Filipino adolescents: A review with implications for research. Philippine Journal of Psychology.

Bank, L.; Marlowe, J. H.; Reid, J. B., Patterson, G. R., \& Weinrott, M. R. (1991). A comparative evaluation of parent-training intervention for families of chronic delinquents. Journal of Abnormal Psychology. 19 (1), 15-33.
Beck, A. T., \& Fernandez, A. (1989). A cognitive therapy of personality disorder. New York: Guilford Press.

Buss, A. H., \& Warren, W. L. (2008). Aggression questionnaire manual. US: Western Psychological Services.

Corado, M.A. (2004). Cognitive/behavioral modification program for aggressive children in conflict with the law. (Unpublished doctoral dissertation) University of Sto. Tomas, Manila, Philippines.

Cothern, L., Lipsey, M. W., \& Wilson, D.B. (2000). Effective intervention for serious juvenile offenders. Juvenile Justice Bulletin.

Escamilla A. G. (1998). A cognitive approach to anger management for juvenile offenders. Journal of Offender Rehabilitation. 27: 199208.

Farrington, D. P., \& Welsh, B. C. (2007). Saving Children from a life of crime. Early risk factors and effective interventions. New York: Oxford University Press.

Goldstein, N. E., Dovido A., Kalbeitzer, R, Weil J., \& Strachan, M. (2007). Anger management for female juvenile offenders: Results of a pilot study. Journal of Forensic Psychology Practice. 7(2):2-28.

Hughes GV. (1993). Anger Management Program Outcomes. Research on Programming Issues, 5, 5-9.

Hunter D. (1993). Anger Management in Prison: An Evaluation: Research on Offender Programming issues, 5, 3-5.

Ireland, J.L. (2004). Anger management therapy with male offenders: An evaluation of treatment outcome. Aggressive Behavior, 30, 174-185. 
Larson, J. D., Calamari, J. E., West, J. G., \& Frevert, T. A. (1998). Aggression management with disruptive adolescents in the residential setting: Integration of a cognitive-behavioral components. Residential Treatment for Children and Youth. 15(4), 1-9.

McBurney, D.H. (2001). Research methods. CA. USA: Wadsworth/Thomson Learning, Inc.

Mosquito, J.R. (2009). Handling child in conflict with the law (RA 9344): Roles of the barangay and SK. Quezon City, Philippines: Central Book Supply. National Youth Violence Prevention Resource Center

Owen, T., \& Fox, S. (2011). Experience of shame and empathy in violent and non-violent offenders. The Journal of Forensic Psychiatry and Psychology, Vol. 12, No. 4, p 551563.

Owen, J., Quirk, K., \& Hilsenroth, M. (2012). Working through: Insession processes that promote between-session thoughts and activities. Journal of Counseling Psychology, 59(1), 161-167.

Schumacher, M., \& Kurz, G. (2000). The 8\% solution: Preventing serious, repeat juvenile crime. USA: Sage.
Sedrpoushan, N., Navabijeja, S., Shafiabady, A., \& Iravani, M. R. (2012). A comparative study of the impact of emotional focused therapy and stress inoculation training on reduction of anger in delinquent adolescents. Journal of Basic and Applied Scientific Research. 2(6), 5604-5615.

Smith, D. C., Larson, J. D., Debaryshe, B., \& Salzman, M. (2000). Anger management for youths: What works and for whom? In D. S. Sandhi (Ed.). Violence in American Schools: A Practical Guide for Counselors, 271-230.

Templa, M.A, Pacaba, M.T., Sarabia, D. G., Montebon, M., Balofinos, A., Tutor, E., Mella, C. F., \& Tornio, S. (2004). Understanding children in conflict with the law: Contradictions in victimization, survivor behaviour, and the Philippine justice system, a study of the situation of children in conflict with the law in Davao.Save the Children-UK.

Towl G. J., \& Dexter, P. (1994). Anger management group work with prisoners: An empirical evaluation. Groupwork, 7, 256-269.

Towl G. J. (1994). Stanko E. (Ed.). Anger control groupwork in prisons. Perspective on violence. Howard Leaue handbooks, I. London: Quarter Books. 